DOI: 10.28995/2227-6165-2017-4-36-42

\title{
О.С. Давыдова
}

кандидат искусствоведения, ведущий научный сотрудник НИИ теории и истории изобразительных искусств РАХ davydov-olga@yandex.ru

\section{ИСТОРИКИ ИСКУССТВА И ПОЭЗИЯ: К ВОПРОСУ О ТВОРЧЕСКОМ МЕТОДЕ Н.А. ДМИТРИЕВОЙ}

Статья посвящена анализу особенностей творческого метода и художественного мышления выдающегося советского и российского искусствоведа Нины Александровны Дмитриевой (1917-2003), позволившим выявить поэтические истоки авторских концепций ученого. Присущий текстам Дмитриевой поиск гармонии между «альфой-видимостью», «альфой-изображением» и «омегой-словом», «омегой-смыслом» рассмотрен в качестве признака индивидуальной версии «камерной» иконологии, опирающейся на поэтику глубокого переживания исследователем художественных образов искусства. Теоретический контекст статьи формируют как искусствоведческие работы Дмитриевой, так и еe суждения о поэзии, поэтические переводы и опыты личного стихотворчества, сохранившиеся в неопубликованных архивных записях ученого.

Ключевъе слова: искусствознание, история и теория искусств, Н.А. Дмитриева, поэзия, поэтическое мышление, художественное восприятие, интерпретация, визуальный образ, вербальный образ, иконология
The article is devoted to the analysis of the features of the creative method and artistic thinking of the outstanding Soviet and Russian art historian Nina Alexandrovna Dmitrieva (1917-2003), which made it possible to reveal the poetic sources of the author's concepts of the scientist. Texts written by Dmitrieva are inherent in the search for harmony between the image and the word, meaning, which in the article is considered as a sign of an individual version of the "chamber" iconology, based on the poetics of a profound experience by the researcher of artistic images of art. The theoretical context of the article is shaped as Dmitrieva's art criticism, as well as her judgments about poetry, poetic translations and the experiences of personal poetry preserved in unpublished archival records of the scientist.

Keywords: art studies, history and theory of art, N.A. Dmitrieva, poetry, poetic thinking, artistic perception, interpretation, visual image, verbal image, iconology

Поэзии нет, если мы ее не вносим сами в любую вещь.

Н.А. Дмитриева

Свое размышление мне бы хотелось начать несколько неожиданными в контексте разговора о классической школе советского искусствознания словами Нины Александровны Дмитриевой (1917-2003), которые одновременно открывают как скрытые источники ее постоянной внутренней работы над пониманием языка искусства, так и дают русскоязычный вербальный облик поанглийски написанному стихотворению Уильяма Батлера Йейтса «Отплытие в Византию» (1926), чаще всего переводимого как «Плавание в Византию (или Византий)»:

Здесь старикам нет места. Предназначен

Для юности беспечный хоровод:

Лес полон птиц, в ручьях форели скачут,

Минутной жизни плоть хвалу поет;

Кто чувственною музыкой захвачен

И увлечен в ее водоворот,

Тем все равно, что там, за гранъю лет,

Вневременный воздвигнул интеллект [Дмитриева, 1974, б.п.].

(C) Давыдова О.С., 2017

* Исследование выполнено в рамках гранта РГНФ, проект 16-04-00087 
O.S. Davydova Art historians and poetry:

\section{to the question of the creative method of N.A. Dmitrieva}

Появление перевода этого стихотворения в судьбе Дмитриевой интересно во многих отношениях, но прежде всего обозначим потенциал, обнаруживаемый в нем с точки зрения искусствоведческих размышлений о самой Нине Александровне. Люди, чья жизнь связана с творческим отношением к письменному слову, как бы ни было успешно их перо при жизни, не могут не думать о посмертной участи написанного. И даже если сам автор внутренне укрывается от этого вопроса, время с объективной неумолимостью проверяет и утверждает ответы на практике. Те акценты, которые поставила Дмитриева в переводе приведенного из Йейтса отрывка, как-то сами собой подводят к жесткому, но сущностно важному вопросу: достигают ли сочинения Нины Александровны масштаба вневременности и каковы их отношения с ныне столь полюбившейся общественному сознанию категорией актуальности?

Автор «Краткой истории искусств» (1-е изд. 1968), серьезных монографических исследований о Михаиле Врубеле, Винсенте Ван Гоге, Пабло Пикассо, Дмитриева была не только внимательным к деталям историком искусства, но и тонким аналитиком, искателем смыслов художественных образов, теоретические подходы которого нашли выражение в создании таких до сих пор не потерявших актуальность книг, как «Изображение и слово» (1962) и «Послание Чехова», изданной в 2007 году посмертно (список публикаций, составленный в хронологическом порядке, см.: [Дмитриева, 2009, с. 514-517]). Особое место среди сочинений Дмитриевой, подтверждающих данную характеристику, занимает и последняя на текущий момент публикация сборника ее статей «В поисках гармонии. Искусствоведческие работы разных лет», осуществленная в 2009 году. Без чрезмерных метафизических рассуждений, без ложного впадения в «декоративный абсурдизм» в большинстве статей, вошедших в подборку этого издания, исследовательнице удавалось создать атмосферу естественного инобытия искусства, всегда хранящем «что-то от вечности» [Дмитриева, Автопортреты..., 2009, с. 167]. Обращение в условиях советской действительности к таким личностям как Михаил Врубель, творчество которого послужило темой ее первой диссертации (не защищенной), или Пабло Пикассо - достаточно яркое свидетельство самостоятельности и независимости художественных вкусов искусствоведа, жившего в стране с официальным курсом на «реализм» социально-передвижнического толка. Естественность, с которой Нина Дмитриева пишет о лирических «противочувствиях» Гийома Аполлинера [Дмитриева, Опыт самопознания, 2009, с. 224-226], о «переживании таинственности мира» [Дмитриева, Впечатление от выставки..., 2009, с. 411] у Марка Шагала, о пришедшейся не ко времени «певучей гармонии» [там же, с. 414] Павла Кузнецова, о царстве метаморфоз Павла Филонова, подлинное значение которого как «большого и совсем особенного художника XX века» [там же, с. 410] не было еще до конца понято даже специалистами, отличается проницательностью искусствоведческого взгляда и зоркостью «очеркиста», интуитивно ощущающего произведение не только как факт истории искусства, но и как органичный художественный образ (в статье «Живое слово критика» о характере своего искусствоведческого призвания Дмитриева пишет: «В качестве искусствоведа и критика я не хотела бы чувствовать себя ни толмачем, ни присяжным советчиком, ни приводным ремнем какого-то механизма, ни даже генератором. Я предпочла бы быть не генератором, а литератором; просто автором “деловой прозы”, если угодно - очеркистом» [Дмитриева, Живое слово критика, 2009, c. 423]).

Однако, прежде чем перейти к индивидуальному знакомству с трудами Дмитриевой и к анализу актуальных с научной точки зрения проблем, поднимавшихся ею в работах, на мой взгляд, необходимо рассмотреть вопрос того внутреннего источника, который, незримо для читателей, позволял Нине Александровне выйти за узко локальные границы своего времени и сформировать взгляд на изобразительное искусство как на умение «видеть за внешним внутреннее», позволяя «читать в мире видимостей» [Дмитриева, 1962, с. 68]. Для этого еще раз вернемся к Йейтсу и поговорим о поэзии, которая и была, на мой взгляд, таким источником.

Казалось бы, откуда мог возникнуть интерес к ирландскому поэту, близкому к символистскому мироощущению, «последнему романтику» [Кружков, 2012, с. 6] (как он сам себя называл), 


\section{О.С. Давыдова Историки искусства и поэзия:}

$\kappa$ вопросу о творческом методе Н.А. Дмитриевой

поэту-жрецу, мистику, верившему в подлинное существование невидимой внутренней жизни художника, постоянно «концентрировавшего мысль на душах» [Йейтс, 2012, с. 273] и пытавшегося всем своим творчеством сдвинуть мир с материалистических опор. Однако, по-моцартовски ясному концептуальному миру Дмитриевой психологически насыщенный образный мир Йейтса был не чужд. Творчеством поэта, автора сборников «Ветер в камышах» (1899), «Башня» (1928), «Винтовая лестница» (1933), трактата «Видение» (1925), Нина Александровна начала интересоваться в первой половине 1970-х годов, сделав около 15 самостоятельных переводов его стихотворений (одно из первых дневниковых упоминаний о поэте относится к 13 февраля 1974; отмечу, что в советское литературоведение Йейтс стал проникать с конца 1960-х годов). В каком-то смысле Нина Александровна была такой же упрямой идеалисткой, как и ирландский «поэтический старовер». Неслучайно, на ассоциативном уровне что-то от автопортретного ощущения волевого упорства собственной личности проступает в стихотворении самой Дмитриевой «Буйвол»: «О, если бы знать, / Что не зря мы ходим по кругу / С завязанными глазами, / Что на чьих-то полях от этого / Влажно зазеленеет рис» [Дмитриева, до 1977, б.п.]. Вчитываясь на современном этапе в характеристики, данные Дмитриевой Александру Иванову, Михаилу Врубелю, Ван Гогу, Ци Байши, Данте, Антону Чехову или Федерико Феллини, вдумываясь в ее формулировки теоретических проблем искусствознания, естественно приходишь к мысли, что проницательность сделанных Ниной Александровной обобщений есть плодупрямого непрерывного погружения их автора во внутренний скрытый план жизни художественных образов. И одним из главных источников на пути обретения понимания языка искусства, в том числе и научного понимания, для Дмитриевой, судя по всему, были психологические тайники поэзии, сопровождавшей ее на протяжении всей жизни Непосредственно архивные подтверждения устойчивого интереса Дмитриевой к поэзии относятся к середине 1930-х годов. Уже в 1-ой тетради дневника 1936-1939 годов Нина Александровна записывает принципиально важную для ее отношения к искусству мысль, которую вообще можно воспринять как жизненное кредо: «Поэзии нет, если мы ее не вносим сами в любую вещь» [Дмитриева, до марта 1938, с. 9]. Это убеждение окружает подлинно органичная ему атмосфера, сформированная выписками из стихотворений Шарля Бодлера, Редьярда Киплинга, Анны Ахматовой, Евгения Баратынского, Иоганна Гёте. Вообще, на страницах «Дневников» Дмитриевой с 1936 по 1986 годы дружно соседствуют поэты-романтики и запрещенные в советское время символисты, древнегреческая лирика чередуется с отрывками из Горация, Данте и «Дон Кихота» Сервантеса - романа-метафоры о неизживаемой поэтической силе идеалов. Именно поэзия, на мой взгляд, и была источником той кочующей поразным видам искусства, не имеющей «местапрописки» творческой интуиции, которая в условиях материалистически ориентированной советской реальности, позволяла Нине Александровне в любом подлинном произведении искусства ощутить «путь в невозможное», порыв к рационально необъяснимому. Благодаря присутствию этого поэтического элемента, в искусствоведческих книгах и статьях Дмитриевой отсутствует самое страшное для бессмертия письменного слова начало - в них нет автоматической механичности отношения к художественным образам тех героев, о которых она пишет, в них всегда ощутим индивидуальный пластический оригинал и его альтернативно осмысленный в границах личности автора вербальный двойник. Говорить об отношении Дмитриевой к ирреальным категориям жизни дело отдельного и, может быть, не совсем искусствоведческого исследования, но именно для понимания ее масштаба как ученого-искусствоведа, понимания источника проницательности ее суждений немаловажное значение имеет такая сугубо иррациональная область как поэзия. 10 января 1958 года Дмитриева записывает перевод стихотворения Генриха Гейне «Двойник» (1823-1824, опубликовано в 1826), в котором как раз проявляется ее стремление видеть и вербализировать смыслы. Интересно отметить, что в отличие, например, от переводов Иннокентия Анненского (опубликовано в 1904) и Александра Блока (1909, опубликовано в 1911), конкретнее передающего драматическую ситуацию любовного переживания, поэтическая версия Дмитриевой наделена более широким метафорически-философским контекстом размышлений о жизни вообще, о трагедии 
O.S. Davydova Art historians and poetry:

\section{to the question of the creative method of N.A. Dmitrieva}

ухода того, что казалось неотъемлемой сущностью внутреннего «Я» и было единственно возможным, хотя и приносящим боль счастьем - об уходе поэзии неуловимого вдохновения: «Тихая ночь; переулки пустынны; / В этом доме жила моя звезда. / Давным-давно он ею покинут, / А все стоит, как стоял тогда. / И кто-то стоит под окнами дома, / Ломает руки, взор подняв к небесам... / Его лицо мне странно знакомо / Я узнаю: ведь это я сам. / О, ты, двойник! Ты, тень моя злая! / Зачем передразнивать страстный бред, / Которым я терзался, сгорая, / В безумные ночи прошлых лет» [Дмитриева, 10 января 1958, б.п.]. Интерпретационный характер перевода Дмитриевой «Двойника» свидетельствует о том, что ей была присуща вера в реальность собственного воображаемого «я» как в нечто нематериальное, в реальность того внутреннего мира, психологически верный двойник которого способен воплотиться в произведении искусства (отсюда и такое глубокое понимание пламенной фантасмогоричности творческого мира Александра Иванова или Михаила Врубеля [Дмитриева, Библейские этюды..., 2009; Дмитриева, 1984]). В определенном смысле, по своей внутренней природе предмет исследования искусствоведа - утопия, запечатленная языком искусства мечта, поэтому и методы ее восприятия будут постоянно обновляться, но актуальность мысли, ранее запечатленной в слове, от этого не угасает, тем более, если в ней самой, как в мысли Дмитриевой, был поэтический масштаб понимания уникальности творческого высказывания.

Таким образом, поэзия, судя по всему, была одним из источников жизненной философии Дмитриевой. Будучи внесенной в восприятие искусства, она во многом провоцировала интерес Нины Александровны к исследованию сложной диалектики художественных образов, природы их смыслов и языковых особенностей воплощения. Основные проблемы, волнующие Дмитриеву, до сих пор сохраняют свою насущность как в искусствознании, так и в живом процессе развития современного искусства. Конечно, внешние модификации неизбежны, но вопросы, связанные с пониманием взаимоотношений слова и изображения, вопросы синтеза и сближения искусств, проблема интерпретации как открытой и непрерывно развивающейся категории искусствоведческого анализа, на самобытном уровне поставленные Дмитриевой уже в книге «Изображение и слово» (1962), до сих пор не потеряли своей актуальности. Обозначенный круг проблем был характерен прежде всего для развития западноевропейского искусствознания XX века (среди советских предшественников Дмитриевой на этом пути прежде всего необходимо назвать Михаила Алпатова). Однако и в европейском контексте поэтика исследований Дмитриевой не кажется чем-тоустарелым, сугубо связанным с локальной ситуацией советского времени.

Одной из ведущих проблем гуманитарной мысли XX века была попытка понять смыслообразующие особенности визуального языка, но именно поиск смысла, заключенного в художественном образе, проходит и через все этапы профессиональногоразвития Дмитриевой. Даже если на поверхностном уровне вспомнить такие хрестоматийные труды, как «Об искусстве и знаточестве» Макса Фридлендера (1946), «Искусство и визуальное восприятие» Рудольфа Арнхейма (1954, пер. - 1974), «Смысл и истолкование изобразительного искусства» (1957) Эрвина Панофского, «Искусство и иллюзия. Опыт психологического изучения изображения» (1956) или «Образ и глаз» (1989) Эрнста Гомбриха, «Искусство видеть» Джона Бергера (1972), «Машину зрения» Поля Вирильо (1988) и целый ряд исследований уже наших современников, то нельзя не отметить, что, так или иначе, в них осуществлено намерение придать зрению духовно содержательный аспект, открыть за художественной видимостью внутренний смысл творческого синтеза натуры и ее субъективного восприятия художником. Тенденции преодолеть недооценку зрительного восприятия как интеллектуального процесса, в основе которого лежит рационально-мыслительный и чувственноэмоциональный опыт, характерны и для искусствоведческой позиции Дмитриевой. В одной из глав книги «Изображение и слово» Нина Александровна выделяет два способа «смотрения» на мир «эстетически настроенного глаза» - чисто информационный и углубленно созерцательный [Дмитриева, 1962, с. 176]. В соответствии с этой характеристикой можно сказать, что аналитическому методу восприятия искусства самой Дмитриевой ближе вторая модель, во многом обуславливающая высшее, по мнению ученого, для любого произведения искусства качество - выразительность. 


\section{О.С. Давыдова Историки искусства и поэзия:}

к вопросу о творческом методе Н.А. Дмитриевой

В этом подходе нельзя не заметить перекличек с эстетической системой восприятия искусства Арнхеймом, позиции которого во многом близки Дмитриевой. Однако если у Арнхейма понятие выразительность как венец художественного языка [Арнхейм, 1974, с. 374-386] носит объективную, несколько условно абсолютизированную форму, то Дмитриева под выразительностью понимает субъективно живой процесс в душе и сознании художника, силу его эмоционального переживания, его косвенно выраженное (в отличие от литературы) осознание предмета: «Главное отличие метода изобразительного искусства <...> от литературного состоит прежде всего в том, что оно непосредственно изображает не впечатления от предметов, не размышления над предметами, а подобия самих предметов в их чувственном бытии, мысли же и переживания сообщаются воспринимающему опосредованно, через эту чувственную форму» [Дмитриева, 1962, с. 47], - пишет Дмитриева. За произведением искусства Нина Александровна стремится прежде всего увидеть «мысль-переживание» [там же, с. 46], которая и определяет индивидуальный характер образа. Вообще, как в «Изображении и слове», так и в последней, посмертно изданной книге «Послание Чехова» Дмитриева выдвигает ряд самостоятельно найденных понятий, которые на интуитивном уровне перекликаются не только с гештальтпсихологией Арнхейма, но и с теорией вчувствования Вильгельма Воррингера, или, например, с «лингвистикой визуального образа» Гомбриха (подробнее см.: [Gombrich, 1960; The Language of Art, 1991]). Она пишет о «мыслях-переживаниях», о визуальных понятиях, об изобразительных словах, о мысленном зрении и мысленном слушании [Дмитриева, 1962, с. 22] (вслушивании в образ), о художественной форме как субстанции, «излучающей подвижные смысловые волны» [Дмитриева, 2007, с. 22]: «Одно из важных значений изобразительного искусства заключается в том, что оно учит видеть - видеть за внешним внутреннее, учит читать в мире видимостей» [Дмитриева, 1962, с. 68]. Для Дмитриевой, как и для Делакруа, «искусство представляет собой как бы осязаемую реальность, полную в то же время тайны» (Дневник Делакруа, цит. по: [Дмитриева, 1962, с. 50]).

С определенной долей условности об искусствоведческом своеобразии Дмитриевой можно говорить как о камерном варианте иконологии - камерной, потому что наибольшей проникновенности синтетического анализа она достигает именно на уровне прямого частного общения с самим произведением искусства (и в меньшей степени на уровне пространственноисторических характеристик). Смысловой масштаб суждений Нины Александровны основывается на постижении индивидуального характера произведения искусства - на вчитывании или всматривании в творческий мир. Именно поэтому, возможно, ей и был интересен Йейтс, да и вообще вся поэтическая сфера творчества, сосредоточенная на передаче молчаливо осознанных и синтетически выраженных настроений души: «Произведение изобразительного искусства, пишет Дмитриева, - двуедино: оно и подражание природе и создание человеческого духа, и обе стороны этого единства должны находиться в гармонии» [там же, с. 68]. Конечно, стоит отметить, что понимание взаимосвязи духовного и чувственного у Нины Александровны впитало в себя и оттенок времени - «все духовное имеет своим источником чувственное» [там же, с. 165] - пишет она в «Изображении и слове». Отчасти эта позиция кажется близкой и любимому писателю Дмитриевой Чехову, иррациональные моменты прозы которого словно завуалированы логически стройной стилистической структурой. В случае с Дмитриевой подобная последовательность возникновения явлений во многом стала причиной двойственного и не совсем доверительного отношения ученого к символизму эпохи модерна [Дмитриева, 1984, с. 8-18], в котором доминирует иная последовательность сущностных зависимостей - все чувственное имеет источником духовное. Однако данные нюансы не так часты в работах Дмитриевой, эстетически преодолевающей плененность научной мысли идеологическими критериями времени.

В заключение еще раз подытожу: в сущности, одной из главных и постоянных тем размышлений Дмитриевой была проблема интеллектуальных пределов искусства в зависимости от природы его творческого языка - неисчерпаемая и по-прежнему манящая тема, в основе которой лежат вопросы интерпретационного характера. Именно восприятие и анализ художественного произведения как 
O.S. Davydova Art historians and poetry:

\section{to the question of the creative method of N.A. Dmitrieva}

отражения динамичной системы творческого мышления и обуславливает своеобразие места Нины Александровны Дмитриевой в развитии отечественного искусствознания.

Автор выражает особую благодарность Светлане Федоровне Членовой, хранителю и исследователю архива Н.А. Дмитриевой, за разрешение использовать неопубликованные записи искусствоведа, а также за консультацию и помощь в работе над статьей.

\section{ИСТОчНИкИ}

1. Дмитриева Н.А. Дневник (рукопись). Тетрадь 1. 1936-1939. Архив семьи Н.А. Дмитриевой. Запись до марта 1938.

2. Дмитриева Н.А. Дневник (рукопись). Китайский ежегодник. 1958-1967. Архив семьи Н.А. Дмитриевой. Запись от 10 января 1958.

3. Дмитриева Н. Изображение и слово. - Москва: Искусство, 1962.

4. Дмитриева Н.А. Рукопись перевода У.Б. Йейтса «Отплытие в Византию». Архив семьи Н.А. Дмитриевой. 1974.

5. Дмитриева Н.А. Рукопись стихотворения «Буйвол». Архив семьи Н.А. Дмитриевой. До 1977.

6. Дмитриева Н.А. Михаил Александрович Врубель. - Ленинград: Искусство, 1984.

7. Дмитриева Н.А. Послание Чехова. - Москва: Прогресс-Традиция, 2007.

8. Дмитриева Н. В поисках гармонии. Искусствоведческие работы разных лет. - Москва: Прогресс-Традиция, 2009.

9. Дмитриева Н. Автопортреты Ван Гога (1972) // Дмитриева Н. В поисках гармонии. Искусствоведческие работы разных лет. - Москва: Прогресс-Традиция, 2009. - С. 165-172.

10. Дмитриева Н. Живое слово критика (1977) // Дмитриева Н. В поисках гармонии. Искусствоведческие работы разных лет. - Москва: Прогресс-Традиция, 2009. - С. 421-424.

11. Дмитриева Н. Впечатления от выставки «Москва - Париж» (1982) // Дмитриева Н. В поисках гармонии. Искусствоведческие работы разных лет. - Москва: Прогресс-Традиция, 2009. - С. 401-420.

12. Дмитриева Н. Опыты самопознания (1984) // Дмитриева Н. В поисках гармонии. Искусствоведческие работы разных лет. - Москва: Прогресс-Традиция, 2009. - С. 215-247.

13. Дмитриева Н. Библейские этюды Александра Иванова (2001) // Дмитриева Н. В поисках гармонии. Искусствоведческие работы разных лет. - Москва: Прогресс-Традиция, 2009. - С. 85-127.

14. Йейтс У.Б. Anima mundi // Йейтс У.Б. Винтовая лестница / Пер. с англ. Г. Кружкова, В. Ряполовой, Т. Стамовой, А.

Ливерганта. - Москва: Книжный Клуб Книговед, 2012. - С. 271-286.

\section{ЛИТЕРАТУРА}

1. Арнхейм Р. Искусство и визуальное восприятие / Общ. ред и вст. ст. В.П. Шестаков. - Москва: Прогресс, 1974.

2. Кружков Г. «Сохранить в душе ирландство» // Йейтс У.Б. Винтовая лестница / Пер. с англ. Г. Кружкова, В. Ряполовой, Т. Стамовой, А. Ливерганта. - Москва: Книжный Клуб Книговед, 2012. - С. 5-14.

3. Gombrich E.H. Art and illusion. A Study in the Psychology of Pictural Representation. - New York: Pantheon Books, 1960.

4. The Language of Art. Cambridge Studies in Philosophy and the Arts / Ed. by S. Kemal and I. Gaskell. - Cambridge and New York: Cambridge University Press, 1991.

\section{SOURCES}

1. Dmitrieva N. Avtoportrety Van Goga [Self-portraits of Van Gogh] (1972) in Dmitrieva N. V poiskah garmonii. Iskusstvovedcheskie raboty raznyh let [In search of harmony. Art criticism works of different years]. Moscow, Progress-Tradiciya, 2009. Pp. $165-172$.

2. Dmitrieva N. Biblejskie etyudy Aleksandra Ivanova [Biblical Studies by Alexander Ivanov] (2001) in Dmitrieva N. V poiskah garmonii. Iskusstvovedcheskie raboty raznyh let [In search of harmony. Art criticism works of different years]. Moscow, ProgressTradiciya, 2009. Pp. 85-127.

3. Dmitrieva N.A. Dnevnik (rukopis). Kitajskij ezhegodnik. 1958-1967. Archiv naslednikov N.A. Dmitrievoj. Zapis ot 1o yanvarya 1958. [Diary (manuscript). Chinese Yearbook. 1958-1967. The Archives of Dmitrieva’s Family. Record of January 10, 1958].

4. Dmitrieva N.A. Dnevnik (rukopis). Tetrad 1. 1936-1939. Archiv naslednikov N.A. Dmitrievoj. Zapis ot marta 1938. [Diary (manuscript). Notebook 1. 1936-1939. The Archives of Dmitrieva's Family. Record until March 1938]. 


\section{О.С. Давыдова Историки искусства и поэзия:}

5. Dmitrieva N. Izobrazhenie i slovo [Image and word]. Moscow, Iskusstvo, 1962.

6. Dmitrieva N.A. Mihail Aleksandrovich Vrubel [Mikhail Alexandrovich Vrubel]. Leningrad, Iskusstvo, 1984.

7.Dmitrieva N.Opyty samopoznaniya [Experience of self-knowledge](1984) in Dmitrieva N. Vpoiskah garmonii. Iskusstvovedcheskie raboty raznyh let [In search of harmony. Art criticism works of different years]. Moscow, Progress-Tradiciya, 2009. Pp. 215-247.

8. Dmitrieva N.A. Poslanie Chehova [The Epistle by Chekhov]. Moscow, Progress-Tradiciya, 2007.

9. Dmitrieva N.A. Rukopis perevoda W.B. Yeatsa "Otplytie v Vizantiyu". Archiv naslednikov N.A. Dmitrievoj. 1974. [Manuscript of translation «Sailing to Byzantium» by W.B. Yeats. The Archives of Dmitrieva's Family. 1974].

10. Dmitrieva N.A. Rukopis stihotvoreniya "Bujvol". Archiv naslednikov N.A.Dmitrievoj.Do 1974. [Manuscript of the poem "Buffalo". The Archives of Dmitrieva's Family. Until 1977].

11. Dmitrieva N. V poiskah garmonii. Iskusstvovedcheskie raboty raznyh let [In search of harmony. Art criticism works of different years]. Moscow, Progress-Tradiciya, 2009.

12. Dmitrieva N. Vpechatleniya ot vystavki "Moskva - Parizh"[Impressions from the exhibition "Moscow - Paris"] (1982) in Dmitrieva N. V poiskah garmonii. Iskusstvovedcheskie raboty raznyh let [In search of harmony. Art criticism works of different years]. Moscow, Progress-Tradiciya, 2009. Pp. 401-420.

13. Dmitrieva N. Zhivoe slovo kritika [The living word of the critic]. (1977) in Dmitrieva N. V poiskah garmonii. Iskusstvovedcheskie raboty raznyh let [In search of harmony. Art criticism works of different years]. Moscow, Progress-Tradiciya, 2009. Pp. 421-424. 14. Yeats W.B. Anima mundi in Yeats W.B. Vintovaya lestnica [Spiral staircase]. Per. s angl. G. Kruzhkova, V. Ryapolovoj, T. Stamovoj, A. Liverganta. Moscow, Knizhnyj Klub Knigoved, 2012. Pp. 271-286.

\section{REFERENCES}

1. Arnheim R. Iskusstvo I Visualnoe vospriatie [Art and visual perception]. Red. i vst. st. V.P. Shestakov. Moscow, Progress, 1974.

2. Gombrich E.H. Art and illusion. A Study in the Psychology of Pictural Representation. New York, Pantheon Books, 1960.

3. Kruzhkov G. "Sohranit v dushe irlandstvo" ["To keep Irish soul in mind”] in Yeats W.B. Vintovaya lestnica [Spiral staircase]. Per. s angl. G. Kruzhkova, V. Ryapolovoj, T. Stamovoj, A. Liverganta. Moscow, Knizhnyj Klub Knigoved, 2012. Pp. 5-14.

4. The Language of Art. Cambridge Studies in Philosophy and the Arts. Ed. by S. Kemal and I. Gaskell. Cambridge and New York, Cambridge University Press, 1991. 